\title{
Analysis of Polysaccharides in Cider: Their Effect on Sensory Foaming Properties
}

\author{
J uan J . Mangas, J avier Moreno, Roberto Rodríguez, Anna Picinelli, and Belén Suárez* \\ Centro de Investigación Aplicada y Tecnología Agroalimentaria, Apartado 13, E-33300 Villaviciosa, Spain
}

\begin{abstract}
A feasible spectrophotometric method for determining acidic and neutral polysaccharides in cider is described, and the advantages of this method are examined with respect to precision, accuracy, and detection and quantitation limits. The concentration of nonvolatile and volatile components in cider, together with chemometric techniques such as principal component analysis (PCA), soft independent modeling of class analogy (SIMCA), and partial least squares (PLS), allowed us to typify the ciders on the basis of their foaming properties. Acidic polysaccharide and 1-propanol were the most relevant variables for this purpose.
\end{abstract}

Keywords: Polysaccharides; foaming properties; multivariate techniques; cider

\section{INTRODUCTION}

The production of natural cider represents one of the major economic resources of Asturias. This beverage is made by the traditional method: slow pressing, spontaneous clarification and fermentation, and bottling without stabilization. The usual way of consuming cider is also very traditional; it is poured into a glass from a height of around $1.5 \mathrm{~m}$, the cider beating against the inside wall of the glass. This handling generates some sensory foaming properties which are considered to be of major importance for cider quality. In fact, the majority of the cider-drinking public judges cider by eye as much as by taste and odor, as is the case for the beerdrinking public. In the case of cider, excessive and nonconsistent lacing and/or high foam stability cause a decrease in its sensory assessment.

There are many studies showing the influence of the chemical composition on the foaming properties of fermented beverages (Brissonet and Maujean, 1991; Pueyo et al ., 1995; Andrés-Lacueva et al., 1996). Polysaccharides contribute to the flavor, color, and foaming properties of the product, as they are substances which stabilize foam. In this sense, it has been hypothesized that an increase in local viscosity, promoted by the presence of these macromolecules, hinders the rate of drainage of liquid between bubles. At the same time, the redissolution of other surface-active components from the bubble wall is reduced by the presence of polysaccharides (Bamforth, 1985).

The polysaccharide level in fermented beverages is determined by several factors such as raw material (mainly the state of ripeness of the fruit), prefermentative technology, and the action of yeasts and bacteria during the biotransformation of fruit (Fleet, 1991; Charpentier and Feuillat, 1993; Sponholz, 1993).

The analysis of polysaccharides in fermented beverages and fruit juices is usually preceded by a purification step, using dialysis, ion-exchange columns, or ethanol precipitation as extraction procedures, as reviewed by Segarra et al. (1995). The chemical charac-

* Author to whom correspondence should be addressed. terization of polysaccharide fractions had been accomplished by chromatographic methods such as ionexchange chromatography (Voragen et al., 1982), sizeexclusion chromatography with refractive index detection (Dubourdieu et al., 1986; Hoagland et al., 1997), and gas-liquid chromatography (Ford, 1982; $\mathrm{Ha}$ and Thomas, 1988). However, spectrophotometric methods are the most frequently employed for determining polysaccharides, using phenol (Dubois et al., 1956) and orcinol (Tollier and Robin, 1979) as chromogen reagents for neutral polysaccharides, while an estimation of the acidic polysaccharide fraction may be ascertained by means of the m-hydroxydiphenyl method (Blumenkrantz and Asboe-Hansen, 1973; Robertson, 1979; Kintner and Van Buren, 1982). This reagent is highly selective, allowing to differentiate between acidic polysaccharides and other components present in fruit juices and fermented beverages, such as phenolic compounds (Robertson, 1981).

The objective of this present study was therefore to opti mize an analytical procedure for determining acidic and neutral polysaccharides in cider and to study the influence of cider composition on its foaming properties using chemometric methods.

\section{MATERIALS AND METHODS}

Samples and Chemicals. Twenty samples of cider were collected from the corresponding cider-maker cellars and kept in the experimental cellar until sensory and global parameter analyses. For the rest of the instrumental data, samples were frozen $\left(-20^{\circ} \mathrm{C}\right)$ at the same time as the sensory session and analyzed later on. Acidic polysaccharides (AP) were quantified as galacturonic acid, and neutral polysaccharides (NP) were quantified using arabinose as standard. All reagents, standards, and solutions were of analytical grade.

Analytical Procedures. Global Parameters. Total and volatile acidities and alcoholic content were determined according to the AOAC method (1984) and total polyphenols using the Folin-Ciocalteu procedure (Montreau, 1972).

Polysaccharides. The cider was vacuum-filtered through hydrophilic cotton and was then subjected to precipitation with ethanol (cider:ethanol, 1:5, v/v) in darkness during $24 \mathrm{~h}$ at room temperature. The precipitate was washed twice in ethanol (96\%), using the Molish test to ascertain the absence 
of soluble sugars. The residue was dried in a stream of nitrogen and dissolved in Milli-Q quality water (cider:water, 1:2, for AP and cider:water, 1:5, for NP).

1. Aci dic Polysaccharides. AP determination was carried out using m-hydroxydiphenyl as chromogen reagent, as described by Kintner and Van Buren (1982). The colored solution was degassed in an ultrasonic bath at $20{ }^{\circ} \mathrm{C}$ for $10 \mathrm{~min}$ to avoid the interference of bubbles formed when the reagent and sodium hydroxi de were added. Colorimetric measurements at $523 \mathrm{~nm}$ were done after $15 \mathrm{~min}$ of col or devel opment.

2. Neutral Polysaccharides. NP analysis was carried out using the orcinol-sulfuric method. An aqueous extract (250 $\mu \mathrm{L}$ ) was carefully mixed with $6 \mathrm{~mL}$ of orcinol-sulfuric reagent $(0.2 \%$, w/v, orcinol in $55 \%$, w/v, sulfuric acid) for 2 min using a Vortex mixer. The tubes were then heated in an $85^{\circ} \mathrm{C}$ water bath for precisely $15 \mathrm{~min}$ and immediately cooled in ice-water for $5 \mathrm{~min}$. Subsequently, the tubes were vortexed thoroughly and degassed in an ultrasonic bath at $20^{\circ} \mathrm{C}$ for $10 \mathrm{~min}$, and the absorbance was measured at $423 \mathrm{~nm}$. The orcinol-sulfuric method permits the estimation of total polysaccharides; NP are obtained by taking into account the interference of AP. This interference was evaluated from the calibration curve of galacturonic acid, obtained with the orcinol-sulfuric method, and the concentration of acidic polysaccharides estimated by the m-hydroxydiphenyl procedure.

Chromatography. Major organic acids (lactic and acetic) were analyzed by HPLC according to the method developed by Blanco et al. (1991), using a reversed-phase system and UV detection. Major volatiles (acetaldehyde, ethyl acetate, methanol, 1-propanol, 2-methyl-1-propanol, 1-butanol, and amyl alcohols) were determined by direct injection with a FIDGC system (Mangas et al., 1993).

Sensory Analysis. Seven cider makers were scheduled once a week for 2 months to carry out sensory analyses in 3-h sessions. The ciders were placed in water a few hours before the sensory evaluation so as to reach $14-15^{\circ} \mathrm{C}$ and served to each judge by a professional cider pourer. Cider glasses (height: $12 \mathrm{~cm}$; bottom diameter, $7 \mathrm{~cm}$; top diameter, $9 \mathrm{~cm}$ ) were cleaned up before each session with hot water, thoroughly rinsed with dei onized water, and air-dried.

Participants were asked to score each sensory attribute, using a hedonic 10-point nonstructured scale, and to discuss their opinions afterward. Foaming properties (foam stability plus lacing) were assessed in duplicate. Nonsignificant differences were found among the judges at the $5 \%$ confidence level.

Data Processing. The data were processed using the PARVUS statistical package (Forina et al., 1988). The data matrix was structured with 20 rows representing ciders and 14 columns corresponding to chemical variables (total and vol atile acidities, AP, NP, polyphenols, lactic and acetic acids, acetaldehyde, ethyl acetate, methanol, 1-propanol, 2-methyl1-propanol, 1-butanol, and amyl alcohols). On the basis of the sensory evaluation, samples were categorized as LF (low foaming) and HF (high foaming). LF ciders were those that scored higher than 6, while HF were those that scored below 6 . The data were autoscaled before statistical treatment.

\section{RESULTS AND DISCUSSION}

Polysaccharide Analysis. Three factors with four repetitive determinations were considered in the optimization of the extraction procedure of polysaccharides, namely, temperature (hot and cold extraction), the ratio of added ethanol (1:3 and 1:5 cider:ethanol), and the addition of hydrochloric acid. Hot extraction was conducted in boiling ethanol for $5 \mathrm{~min}$, while cold extraction was carried out at $20{ }^{\circ} \mathrm{C}$ for $24 \mathrm{~h}$ in darkness. The polysaccharide concentration was significantly higher $(p<5 \%)$ when the cold extraction procedure was applied instead of the hot extraction one and when the cider: ethanol ratio of 1:5 was used instead of the 1:3 cider: ethanol ratio $(p<5 \%)$. Several researchers have carried out the precipitation of polysaccharides under acidic
Table 1. Analytical Characteristics of the

Polysaccharide Analysis Procedure

$\begin{array}{lc}\text { repeatability }^{\mathrm{a}} & <2 \% \\ \text { reproducibility } & <3 \% \\ \text { detection limit (mg/L) } & 0.22(\mathrm{AP}) ; 0.51(\mathrm{NP}) \\ \text { quantitation limit (mg/L) } & 0.75(\mathrm{AP}) ; 1.71(\mathrm{NP}) \\ \text { linearity (mg/L) } & 100(\mathrm{AP}) ; 60 \text { (NP) }\end{array}$

a Determined as relative standard deviation from five measurements. ${ }^{b}$ Estimated as mean of the relative standard deviation of each of the samples $(n=20)$ using three replicates; AP, acidic polysaccharide; NP, neutral polysaccharide.

conditions (Usseglio-Tomasset, 1976; Dubourdieu et al., 1981); our results showed a decrease in the polysaccharide concentration when $0.008 \mathrm{M}$ hydrochloric acid was used, especially the acidic fraction. This could be due to the hydrolysis of these macromolecules, which is promoted by the action of the acid (Thibault, 1980). Other compounds such as proteins and polyphenols should not interfere in the determination of polysaccharides, in accordance with the findings obtained by Thibault (1979) and Segarra et al. (1995), since they are present at low concentrations in both cider $(<200 \mathrm{mg} / \mathrm{L}$ for proteins) and the aqueous extracts ( $<40 \mathrm{mg} / \mathrm{L}$ for polyphenols). The accuracy of the precipitation procedure was tested by spiking a sample of cider with pectin from apples (Fluka 76282), reaching a percentage of recovery close to $97 \%$ (RSD < 3\%). Other analytical characteristics of the method optimized are shown in Table 1.

Cider Composition and Foaming Properties. Data Univariate Analysis. The descriptive statistics of chemical variables are shown in Table 2. Apparently, there exist some differences between LF ciders (positively assessed by the panel) and HF ciders (scored negatively by the panel) with respect to their chemical composition. LF ciders presented higher mean values for 1-propanol and lower mean contents for AP and methanol than HF ones. Fisher's test was applied so as to ascertain the most relevant variables for differentiating both categories (LF and HF), and these were found to be 1-propanol and acidic polysaccharide with Fisher weight values of $0.90(p<5 \%)$ and 0.82 ( $p<5 \%$ ), respectively. Figure 1 shows two Box-Whisker plots using the most discriminating variable, namely, 1-propanol; as can be seen in this figure, separation of the two categories may not be achieved by means of univariate treatment based on the 1-propanol content, and hence multivariate treatment was needed.

Factor Analysis of the Internal Structure. Principal component analysis (PCA) was used to reduce the dimensionality of the data matrix and to ascertain the data structure. Five eigenvectors that accounted for $85.3 \%$ of the variance were chosen on the basis of Kaiser's criterion. The analysis of the data structure was done by means of an orthogonal rotation. Figure 2 shows the projection of the original variables and ciders onto the plane formed by the first and third varivectors, respectively. Acidic polysaccharides, methanol, and 1-propanol were the most correlated to the third varivector (correlation coefficients, $0.58,0.52$, and -0.31 , respectively), while volatile acidity, acetic acid, and acetal dehyde were more correlated to the first varivector (correlation coefficients, $0.56,0.51$, and -0.38 , respectively). The distribution of data showed that ciders which belong to the low-foaming class were samples with high 1-propanol and low acidic polysaccharide and methanol contents. The influence of the polysaccharide 
Table 2. Descriptive Statistics of Variables for Cider Categories (LF and HF)a

\begin{tabular}{|c|c|c|c|c|c|c|}
\hline & \multicolumn{3}{|c|}{ LF } & \multicolumn{3}{|c|}{$\mathrm{HF}$} \\
\hline & mean & $\min$ & $\max$ & mean & $\min$ & $\max$ \\
\hline volatile acidity ${ }^{b}$ & 1.54 & 1.07 & 2.60 & 1.36 & 0.55 & 2.12 \\
\hline total aciditya & 3.59 & 3.19 & 3.98 & 4.22 & 2.76 & 5.75 \\
\hline polyphenols ${ }^{d}$ & 1.03 & 0.64 & 1.94 & 0.94 & 0.53 & 1.13 \\
\hline acidic polysaccharide & 28.25 & 14.04 & 44.42 & 184.76 & 25.24 & 539.00 \\
\hline neutral polysaccharide & 165.67 & 106.75 & 244.17 & 172.92 & 118.53 & 234.28 \\
\hline al coholic content $(\%, v / v)$ & 6.3 & 5.8 & 6.9 & 6.4 & 6.2 & 6.7 \\
\hline acetal dehyde & 22.52 & 2.22 & 68.93 & 20.90 & 3.46 & 60.44 \\
\hline ethyl acetate & 101.58 & 62.40 & 145.12 & 106.22 & 49.62 & 182.58 \\
\hline methanol & 70.34 & 44.20 & 104.64 & 103.14 & 23.79 & 163.44 \\
\hline 1-propanol & 24.83 & 11.06 & 40.46 & 13.51 & 7.37 & 27.05 \\
\hline 2-methyl-1-propanol & 23.69 & 15.24 & 35.33 & 27.32 & 8.44 & 55.99 \\
\hline 1-butanol & 5.35 & 1.64 & 7.25 & 5.03 & 1.58 & 8.93 \\
\hline amyl alcohols & 168.49 & 114.88 & 226.29 & 132.88 & 50.71 & 244.52 \\
\hline lactic acide & 4.13 & 3.25 & 5.05 & 3.62 & 3.29 & 4.10 \\
\hline acetic acide & 1.32 & 0.60 & 1.99 & 1.20 & 0.41 & 2.23 \\
\hline
\end{tabular}

${ }^{a}$ Concentration in $\mathrm{mg} / \mathrm{L}(\mathrm{n}=20)$; $\mathrm{LF}$, low foaming; HF, high foaming. ${ }^{\mathrm{b}} \mathrm{g}$ of acetic acid/L. ${ }^{\mathrm{c}} \mathrm{g}$ of sulfuric acid/L. ${ }^{\mathrm{d}} \mathrm{g}$ of tannic acid/L. e Concentration in $\mathrm{g} / \mathrm{L}$.

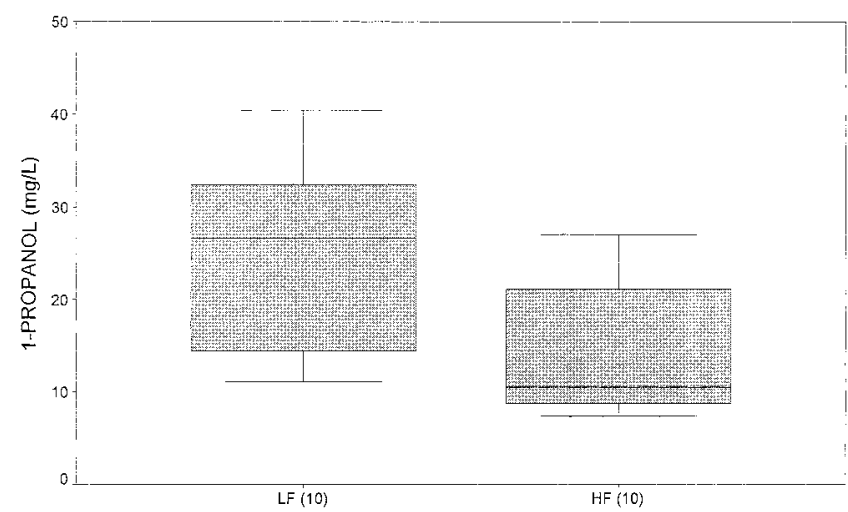

Figure 1. Box plots for each category (LF, low foaming; $H F$, high foaming) using the main discriminating variable (1propanol). The number of samples for each category is included in parentheses.

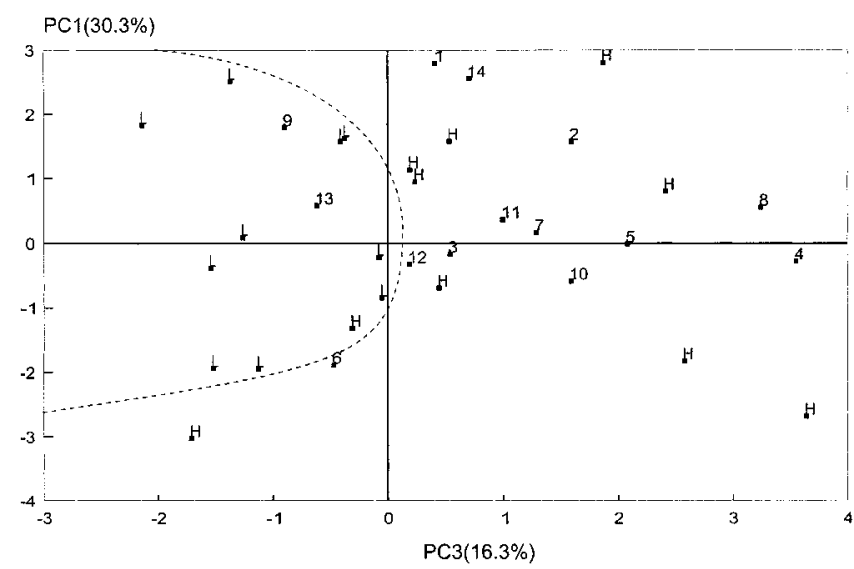

Figure 2. Eigenvector projection of chemical variables and ciders: 1, volatile acidity; 2, total acidity; 3, polyphenols; 4, acidic polysaccharide; 5 , neutral polysaccharide; 6 , acetaldehyde; 7, ethyl acetate; 8, methanol; 9, 1-propanol; 10, 2-methyl1-propanol; 11, 1-butanol; 12, amyl alcohols; 13, lactic acid; 14, acetic acid; L, low-foaming category; $H$, high-foaming category.

level on foam stability in alcoholic beverages has been well- established (Bamforth, 1985). Obviously, the relationship detected between methanol content and foaming properties of cider is explained by the fact that this alcohol is chemically linked to apple pectins. The relationship detected between 1-propanol and the foaming properties of cider shows the necessity of controlling

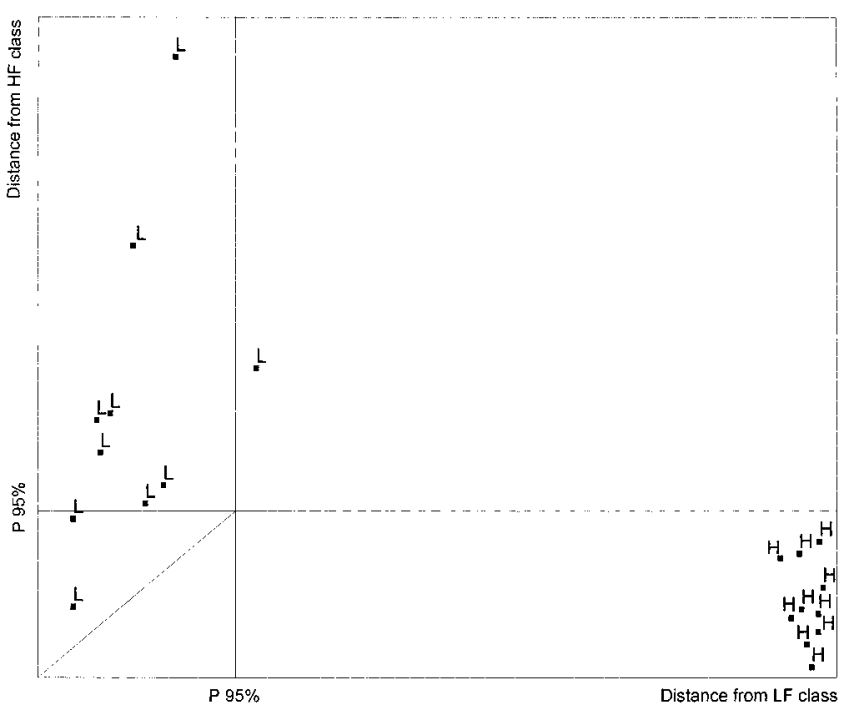

Figure 3. Coomans' diagram for SIMCA analysis ( $L$, lowfoaming category; $\mathrm{H}$, high-foaming category).

the fermentation process by selecting an adequate starter, since it is well-known that the capacity of Saccharomyces to produce 1-propanol is basically controlled by genetic factors (Thornton, 1989).

Soft I ndependent Modeling of Class Anal ogy (SIMCA). Five and six principal components were computed for each classes (LF and HF, respectively) using a SI MCA augmented model, which accounted for $96.4 \%$ and $96.0 \%$ of the variance, respectively. Figure 3 shows a Coomans' diagram where the two SIMCA boxes are displayed. As can be seen, correct classifications were $100 \%$, since all ciders belonging to the LF class ( $\mathrm{L}$ in the figure) are placed above the diagonal, and all ciders bel onging to the $\mathrm{HF}$ class ( $\mathrm{H}$ in the figure) are placed below the diagonal, acidic polysaccharides being the most discriminating variable in accordance with the results obtained by PCA analysis. At the same time, theSIMCA models obtained were highly sensitive $(90 \%$ and $100 \%$ for LF and HF , respectively) and specific ( $100 \%$ and $80 \%$ for $L F$ and $H F$, respectively); thus, a high percentage of ciders classified initially within a category are correctly placed within their SIMCA box, while on the other hand, only a low percentage of ciders categorized initially within a class are accepted within the SI MCA box corresponding to another class. 
Partial Least Squares (PLS). This modeling technique was also employed for typifying ciders on the basis of their foaming properties. The sensory attributes were then subjected to multivariate regression by PLS on the chemical variables. A cross-validation procedure was carried out using three groups for cancellation. The cross-validated explained variance (CVEV) showed a maximum value $(75.0 \%)$ with one latent variable, the square of the multiple linear correlation coefficient $\left(R^{2}\right)$ being $84.7 \%$. The most relevant variables were as follows: acidic polysaccharide, 1-propanol, and total acidity. In agreement with PCA and SI MCA analyses, pectin content was also the most relevant variable in the model constructed from PLS-1 al gorithm. This result is important from the technological point of view, showing the influence of the raw material on the foaming properties of ciders, as the pectin content depends on the degree of ripening of apples.

\section{CONCLUSIONS}

A reliable analytical procedure for analyzing acidic and neutral polysaccharides in cider was optimized. Cold precipitation with ethanol and the absence of hydrochloric acid promoted an increase in the polysaccharide content. The use of multivariate techniques of data analysis, namely, PCA, SIMCA, and PLS, allowed us to ascertain the important role played by the acidic polysaccharide fraction, methanol, and 1-propanol in the typification of ciders on the basis of their foaming properties. Thus, ciders positively scored in sensory analyses were those containing lower methanol and acidic polysaccharide contents and higher 1-propanol contents. Hence, the characteristics of the raw material (apple varieties and their degree of ripening), the prefermentative technology used, which directly influences the pectin level in apple juice, and the activity and type of fermentative yeasts which influence pectolytic activity devel oped in the fermentation media and the 1-propanol content are factors to be taken into account in order to control the foaming properties of cider.

\section{LITERATURE CITED}

Andrés-Lacueva, C.; López-Tamames, E.; Lamuela-Raventós, R. M.; Buxaderas, S.; Torre-Boronat, M. C. Characteristics of sparkling base wines affecting foam behaviour. J . Agric. Food Chem. 1996, 44, 989-995.

AOAC. Beverages: Wines. In Official Methods of Analysis of the Association of Official Analytical Chemists; Williams, S., Ed.; AOAC: Arlington, VA, 1984; pp 220-230.

Bamforth, C. W. The foaming properties of beer. J . Inst. Brew. 1985, 91, 370-383.

Blanco, D.; Morán, M. J .; Gutiérrez, M. D.; Mangas, J.J . Determination of organic acids in apple and cider by liquid chromatography with ordinary and narrow-bore columns. A comparative study. J . Liq. Chromatogr. 1991, 14, 27072719.

Blumenkrantz, N.; Asboe-Hansen, G. New method for quantitative determination of uronic acids. Anal. Biochem. 1973, 54, 484-489.

Brissonet, F.; Maujean, A. I dentification of some foam-active compounds in Champagne base wines. Am. J . Enol. Vitic. 1991, 42, 97-102.

Charpentier, C.; Feuillat, M. Y east autolysis. In Wine Microbiology and Biotechnology; Fleet, G. H., Ed.; Harwood Academic Publishers: Switzerland, 1993; pp 225-242.
Dubois, M.; Gilles, K. A.; Hamilton, J . K.; Rebers, P. A.; Smith, $F$. Colorimetric method for determination of sugars and related substances. Anal. Chem. 1956, 28, 350-356.

Dubourdieu, D.; Hadjinicolaou, D.; Ribéreau-Gayon, P. Les polysaccharides solubles du moût: méthode simple d'appreciation. Evolution au cours de la maturation. Incidence sur les opérations prefermentaires. (Sol uble polysaccharides in musts. A simple estimation method. Changes during maturation and influence on prefermentative operations.) Connaiss. Vigne Vin 1981, 15, 29-40.

Dubourdieu, D.; LLauberes, R.-M.; Ollivier, C. Estimation rapide des constituants macromoléculaires des moûts et des vins par chromatographie liquide haute pression de tamissage moléculaire. (Rapid estimation of macromolecules in musts and wines by size-exclusion HPLC.) Connaiss. Vigne Vin 1986, 20, 119-123.

Fleet, G. H. Cell walls. In The Yeasts. Yeast Organelles; Rose, A. H., Harrison, J . S., E ds.; Academic Press: London, 1991; pp 199-277.

Ford, C. W. A routine method for identification and quantitative determination by gas-liquid chromatography of galacturonic acid in pectic substances. J . Sci. Food Agric. 1982, 33, 318-324.

Forina, M.; Leardi, R.; Armanino, C.; Lanteri, S. In PARVUS. An Extendable Package of Programs for Data Exploration, Classification and Correlation; Elsevier: Amsterdam, 1988.

Ha, Y. W.; Thomas, R. H. Simultaneous determination of neutral sugars and uronic acids in hydrocolloids. J . Food Sci. 1988, 53, 574-577.

Hoagland, P. D.; Konja, G.; Clauss, E.; Fishman, M. L. HPSEC with component analysis of citrus and apple pectins after hollow fiber ultrafiltration. J. Food Sci. 1997, 62, 69-74.

Kintner, P. K.; Van Buren, J. P. Carbohydrate interference and its correction in pectin analysis using the m-hydroxydiphenyl method. J . Food Sci. 1982, 47, 756-764.

Mangas, J . J .; González, Ma . P.; Blanco, D. Influence of cidermaking technology on low-boiling-point volatile compounds. Z. Lebensm. Unters. Forsch. 1993, 197, 522-524.

Montreau, F. Sur le dosage des composés phenoliques totaux dans les vins par la méthode F olin-Ciocalteu. (Analyses for total phenolic compounds in wines by the Folin-Ciocalteu method.) Connaiss. Vigne Vin 1972, 6, 397-404.

Pueyo, E.; Martín-Alvarez, P. J .; Polo, M. C. Relationship between foam characteristics and chemical composition in wines and cavas (sparkling wines). Am. J . Enol. Vitic. 1995, 46, 518-524.

Robertson, G. L. The fractional extraction and quantitative determination of pectic substances in grapes and musts. Am. J . Enol. Vitic. 1979, 30, 182-186.

Robertson, G. L. The determination of pectic substances in citrus juices and grapes by two spectrophotometric methods. J . Food Biochem. 1981, 5, 139-143.

Segarra, I.; Lao, C.; López-Tamames, E.; Torre-Boronat, M. C. Spectrophotometric methods for the analysis of polysaccharide levels in winemaking products. Am. J . Enol. Vitic. 1995, 46, 564-570.

Sponholz, W.-R. Wine spoilage by microorganisms. In Wine Microbi ol ogy and Biotechnol ogy; F leet, G. H., Ed.; Harwood Academic Publishers: Switzerland, 1993; pp 395-420.

Thibault, J. F. Automatisation du dosage des substances pectiques par la méthode au méta-hydroxydiphenyl. (An automated method for the determination of pectic substances.) Lebensm.-Wiss. Technol. 1979, 12, 247-251.

Thibault, J. F. Les substances pectiques. Les Polymères Végétaux; Gauthier-Villars: Paris, 1980; pp 232-251.

Thornton, R. J . New yeast strain from old.-The application of genetics to wine yeasts. Food Technol. Australia 1989, 35, 46-50.

Tollier, M.-T.; Robin, J . P. Adaptation de la méthode à l'orcinolsulfurique au dosage automatique des glucides neutres totaux: conditions d'application aux extraits d'origine végétale. (Adapted orcinol-sulphuric method for automatique analysis of total neutral sugars: conditions for the application to vegetal extracts.) Ann. Technol. Agric. 1979, 28, $1-15$. 
Usseglio-Tomasset, L. Les colloïdes glucidiques solubles des moûts et des vins. (Musts and wines glucidic colloids.) Connaiss. Vigne Vin 1976, 10, 193-226.

Voragen, A. G. J .; Schols, H. A.; De Vries, J. A.; Pilnik, W. High-performance liquid chromatographic analysis of uronic acids and oligogalacturonic acids. J . Chromatogr. 1982, 244, 327-336.
Received for review February 6, 1998. Revised manuscript received October 26, 1998. Accepted October 27, 1998. We are indebted to the FICYT, Projet PA-AGR94-04, and the Association of Asturian Cider Makers for financial support.

J F980107U 